\title{
FOTO CLÍNICA
}

\section{Lipoma gigante}

\section{Giant lipoma}

\section{Aland Bisso-Andradel}

Varón de 42 años, sin antecedentes de importancia, acudió a consulta externa debido a que presentaba una tumoración en la espalda de unos cinco años de evolución, el mismo que tenía un tamaño más o menos constante, similar a un "limón", pero que en los últimos dos años tuvo un crecimiento progresivo.

En el examen se encontró una tumoración subcutánea en la región escapular izquierda de aproximadamente 12 x $14 \mathrm{~cm}$, móvil, indurada (no pétrea), depresible, no dolorosa y sin cambios en la piel suprayacente.

La ecografía y la biopsia confirmaron la presunción de lipoma.

El paciente fue enviado al cirujano de tórax para la extirpación de la lesión.

Los lipomas son tumores subcutáneos benignos de las células grasas (adipocitos) que se presentan como nódulos blandos e indoloros, Por lo general, son solitarios y miden de 2 a $3 \mathrm{~cm}$; sin embargo, ocasionalmente puede hallarse lipomas de $5 \mathrm{~cm}$ o más y se les denomina "lipoma gigante". Los lipomas gigantes son raros. Pueden causar disfunción mecánica, dolor y sensibilidad alterada debido a su tamaño y la compresión resultante de las estructuras vecinas, además de una alteración estética para el paciente. Por lo general, se encuentran en el tronco o extremidades, a veces en el cuello; sin embargo, también pueden ser interóseos, viscerales, intramurales, subfasciales o intermusculares. Las características benignas se pueden registrar en la ecografía, tomografía o resonancia magnética, pero el diagnóstico definitivo es a través del estudio histopatológico.

El diagnóstico diferencial incluye, entre otros, quistes epidermoides, hibernomas, angiolipomas, angiomiolipomas y liposarcomas.

Los hibernomas son masas de grasa parda, benignas y de crecimiento lento, que suelen aparecer en el mediastino o en la espalda y se presentan como una masa de crecimiento lento de 3 a $12 \mathrm{~cm}$ en el adulto.

Los angiolipomas son dolorosos, miden menos de $2 \mathrm{~cm}$ y suelen aparecer en el antebrazo.

Los liposarcomas se presentan con mayor frecuencia como tumores profundos en el retroperitoneo o, clásicamente, en los muslos.

Los lipomas pequeños solo requieren observación clínica y se extirpan cuando se vuelven dolorosos o por motivos estéticos.

Los lipomas gigantes deben tener estudio histopatológico y ser retirados por escisión quirúrgica o liposucción.

I Médico internista, MHA, FACP. Clínica Delgado.
Bisso-Andrade A. Lipoma gigante (Foto clínica). Rev Soc Peru Med Interna. 2019;32(2):80.

https://doi.org//0.36393/spmi.v32i2.224
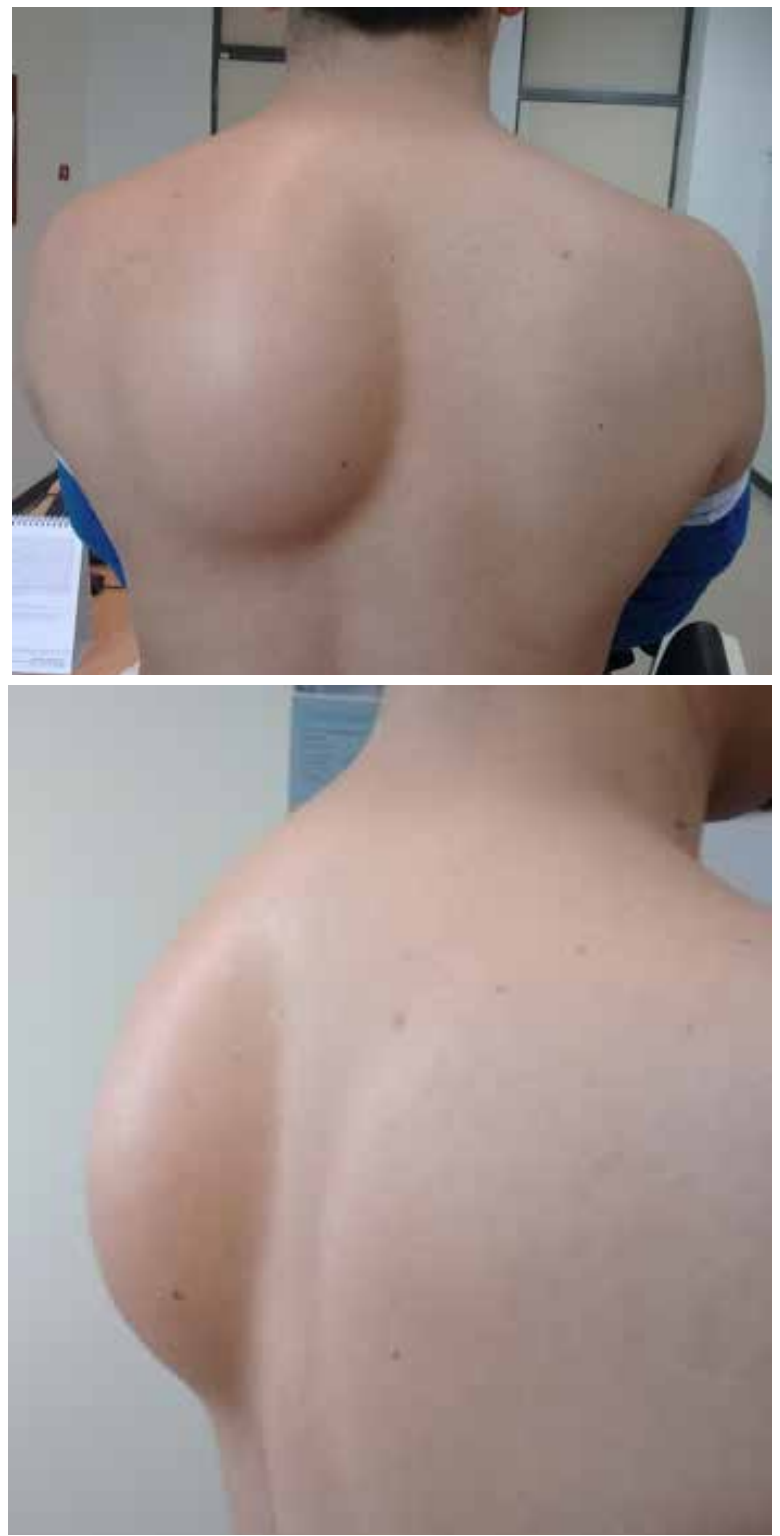

Figura I. Lipoma gigante en la región escapular izquierda.Tumoración subcutánea de $12 \times 14 \mathrm{~cm}$, sin cambios en la piel suprayacente.

\section{REFERENCIAS BIBLIOGRÁFICAS}

I. Kolb L, Rosario-Collazo JA. Lipoma. Source StatPearls [Internet]. Treasure Island (FL): StatPearls Publishing. 2019; Mar 25.

2. Demicco EG. Molecular updates in adipocytic neoplasms $\square$. Semin Diagn Pathol. 2019 Mar;36(2):85-94.

3. Balakrishnan C, Nanavati D, Balakrishnan A, Pane T. Giant lipomas of the upper extremity: Case reports and a literature review. Can J Plast Surg. 2012 Fall; 20(3):e40-I. 